\title{
Political-economic Transitions and the Changing Context of Maternal Health Access in Tanzania: Evidence from DHS Data
}

\author{
Moshi Optat Herman, PhD \\ Fellow in Demography/Population Science \\ London School of Economics and Political Science \\ M.O.Herman@Ise.ac.uk
}

\begin{abstract}
This paper highlights how the effect of household socioeconomic status on utilization of maternal health services changes over time concomitant with transformations of the social context, such as political economic transitions in the case of Tanzania. Using pooled data from four rounds of Demographic and Health Surveys (DHS) from Tanzania, this paper applies multilevel logistic regressions to examine how the effect of household wealth on utilization of medically-assisted birth delivery services (controlling for individual attributes) is mediated by place characteristics (regional wealth and urban/rural residence) and period (liberalization era 1990s vs. Millennium Development Goals era 2000s). With implications on health inequality in transition economies, the analysis finds statistically significant interaction effects between household wealth and place characteristics. The analysis also finds interaction effects between household wealth and period.
\end{abstract}

Keywords: maternal health; health inequality; birth delivery by skilled-staff; Tanzania; Demographic and Health Surveys (DHS)

\section{Résumé}

Ce document démontre comment l'effet des ménages sur l'utilisation de la santé maternelle change avec les transformations sociales (transitions politiques et économiques) en Tanzanie. Les données d'Enquêtes Démographiques de Santé (EDS) et des régressions logistiques multiniveaux indiquent comment la richesse des ménages sur l'utilisation des services d'accouchement (contrôle des attributs individuels) est médiée par les caractéristiques de l'emplacement (région et résidence urbaine/rurale) et la période (libéralisation en 1990 contre Objectifs de Développement du Millénaire en 2000). Avec des implications sur les inégalités de santé dans les économies en transition, l'analyse conclut à des effets d'interaction significatifs entre richesse des ménages et caractéristiques d'emplacement. L'analyse trouve également une interaction entre richesse des ménages et période.

Mots clé: la santé maternelle; inégalités de santé; livraison de naissance par l'homme-personnel; Tanzanie; Enquêtes D émographiques et de Santé (EDS)

\section{Introduction}

Maternal mortality is still a pressing issue in lowincome nations such as Tanzania. Recent initiatives, including the Millennium Development Goals, have brought reduction of maternal deaths to the forefront of global priorities. Tanzania experienced a decline in maternal mortality in the last two decades. Life time risk of maternal mortality decreased from 5.3 in 1990 to 2.6 in 2010 and maternal mortality declined from 870 per 100,000 live births in 1990 to 460 per 100,000 live births in 2010 (W orld Bank 2013).
In low-income nations, the risks of maternal and new born deaths are highly associated with access to basic reproductive health services. Pregnant women with access to prenatal care from medical professionals and those who deliver their newborns under supervision of medically-trained professionals have a relatively low risk of maternal mortality (Khan, Wojdyla, et al. 2006.). The decline in maternal mortality risk in Tanzania between 1990 and 2010, for example, went hand-in-hand with an increase in access to maternal health care. The percentage of women receiving prenatal care in Tanzania increased from $62.2 \%$ in 1992 to $87.8 \%$ in 
2010, and the percentage of births attended by skilled health professionals increased from $43.9 \%$ to $48.9 \%$ in the same time period (World Bank 2013). However, time-trend data show a slight decline in both prenatal care access and proportion of births attended by health professionals in mid to late 1990s before resuming an upward trend again in early 2000s (World Bank 2013).

The observed slight decline in access to maternal health care in the mid-1990s, the period that coincides with liberalization reforms, raises important empirical questions about the relationship between structural political-economic transformation and long-term health outcomes. 0 ne question of interest, for example, is whether the downward trend in the 1990s and the eventual upward trend of increasing access in the 2000s redefined maternal health inequality in the country. For instance, if the decline in use emerged from a decline in maternal services provisions during the economic reforms of the 1990s, was the experience similar across socioeconomic groups?

I used Demographic and Health Surveys (DHS) data on access to maternal health care to shed light on the manner by which utilization was mediated by contextual variables: household wealth, place, and period. Through logistic (multilevel) regression models, I examined three research questions exploring the relationship between shifting social context and utilization of maternal health service during liberalization (1990s) and after liberalization (2000s). First, does the region where one lives impact access to maternal health net of individual and household circumstances? Second, since household wealth is positively associated with access and use of maternal health services (Tawiah 2011), does the effect of household wealth vary by characteristics of the place (region) where one lives? For instance, does the effect of own wealth (household wealth) vary between wealthier regions and poorer regions? And third, does the effect of household wealth on maternal care access vary between the liberalization period (1990s) compared to the post-liberalization/Millennium Development Goals era (2000s)?

This paper thus contributes to the empirical literature on the relationship between politicaleconomic transformations in transitional societies and health outcomes. The particular context of Tanzania's transition to a market economy offers an especially effective backdrop for the stated empirical question. In Tanzania, liberalization called for termination of their rural-centric policies of the centralized economy (ujamaa) era which had a particular emphasis on spatial (rural-urban) equity in access to development services, such as health and education.

\section{Literature review \\ Determinants of utilization of professional maternal health services}

Utilization of professional maternal health services is determined by both demand-side factors, such as preference for professional care over other options, and supply-side considerations, such as availability of a hospital or a clinic within reasonable distance, cost of travel, cost of provided services, etc. There is some evidence that some women in Tanzania would prefer not to use medical professionals for their maternal health needs for varieties of reasons (van Rijsbergen and D'Exelle 2013). However, for the most part, use of professional maternal health services is predicated on accessibility and cost of the given services (Kowalewski, Mujinja, and Jahn 2002), and also on anticipated quality of the services (Kruk, Rockers, et al. 2010). In Tanzania, there is a noted preference for medically-based maternal care over other alternatives, such as seeking care from "traditional" midwives (Mbaruku, Msambichaka et al. 2009). Alternatives to the preferred professional services are only sought when the availability of medical facilities is limited (Mbaruku, Msambichaka et al. 2009). As such, in this paper, use or non-use of professional maternal care services is used as a proxy for availability of such services within a reasonable distance and at an affordable cost.

The available literature on determinants of professional maternal care utilization characterizes users and non-users by demographic factors, household features, and place-of-residence characteristics (Mrisho et al. 2007, Tann et al. 2007, Stephenson et al. 2006, Yanagisawa 2006, Anwar et al. 2005; Magadi 2004; Glei, Goldman and Rodriguez 2003; Magadi et al. 2003, Paul and Rumsey 2002). Education, age, and parity are among the demographic factors associated with maternal health services utilization. Educated mothers are more likely to use professional maternal health because they are more likely to be able to afford the services and they are better informed about the risks associated with not utilizing them. Utilization increases with age but peaks at some point thus exhibiting a curvilinear relationship. There is a negative association between parity and utilization of maternal health services; with every additional child the likelihood of utilizing professional maternal health services decreases. 
Socioeconomic status and household wealth are positively associated with the likelihood of using professional maternal care in Tanzania (Spangler and Bloom 2010) since they influence both the ability to travel to the source and the ability to pay for the cost of the services. Finally, place of residence also determines who utilizes professional maternal health facilities. Residents of rural areas in low-income nations are less likely to utilize such services because of limited access (Tawiah 2011).

\section{Political-economic transitions in Tanzania}

Post-Independence ujamaa villages

In the 1960s, Tanzania adopted a "centralized" political economic system that aimed at creating a collective/communal system of production and distribution of goods and services (ujamaa) and national self-reliance (kujitegemea). Advocated by the first president J.K Nyerere, Ujamaa na Kujitegemea was made official by the Arusha Declaration in 1967 which planned among other things to establish public ownership and control of means of production and exchange, to foster the virtues of equality, and to emphasize on rural development (N yerere 1968, 1973, 1985).

Through ujamaa a village resettlement project was implemented intending to extend "development" to rural areas that had been neglected during the colonial era (Hydén 1980). The Tanzania villagization project was among the largest rural resettlement project ever to be attempted in Africa (Jennings 2008, Scott 1998). Critics have however pointed out that the objective of improving living conditions in the rural areas failed (Schneider 2007, 2010; Scott 1998). Furthermore, the heavily centralized nature of the project led to minimal participation in decision-making and planning at the local level (Shivji and Peter 2003), and at times violation of rural citizens' civil liberties (Schneider 2010).

The impact of ujamaa policies on long term development and equity in access to social services in the country is still an open debate. Particularly, given that ujamaa policies consciously attempted to use rural areas as the focal point of economic production and distribution of social services, it makes one wonder whether discontinuation of the project at the onset of liberalization potentially created new channels of spatial (rural/urban) inequality or exacerbated the already existed disparities.
Structural adjustment and privatization in the 1990s

Similar to other Global South nations, liberalization was implemented in Tanzania under pressure from the International Monetary Fund (IMF) through its "conditional loans" initiatives also known as Structural Adjustment Programs (SAP). Early loan agreements were unsuccessful because the Tanzanian government failed to meet the prescribed conditions (Gibbon 1995, Stein 1991) partly due to ideological contradiction between the prescribed policies and Ujamaa na Kujitegema philosophy. Similar attempts at "home grown" programs, such as the National Economic Survival Program (NESP) from 1981 -1982 also failed to materialize (Amani, Wangwe et al. 2006; Gibbon 1995).

Eventually, successful loan agreements between the IMF and Tanzania government included a three year Structural Adjustment Facility (SAF) from 19871990 and Enhanced Structural Adjustment Facility (ESAF) in 1991 (Amani, Wangwe et al. 2006). Through these loan agreements Tanzania officially transitioned to liberalization in the 1990s. ESAF introduced the typical template of "structural adjustment" measures including reducing government's involvement in the economy through privatization, liberalization of financial markets and banking system in order to create an enabling environment for foreign investment, and budget austerity measures.

The crucial structural changes from these policies which would have impacted health access are privatization of state-owned enterprises and budget austerity. Privatization has been noted to lead to an increase in unemployment (Sillanes and Chong 2002) and Tanzania was not an exception on this regard (Mkenda 2005, Mwandenga 2000). Privatization thus has an indirect effect on health via its effect on income fluctuations that are brought about by the increases in unemployment that accompany it. Budget austerity, on the other hand, impacts health access directly as it leads to reduced government spending on social services.

Early empirical studies highlighted a detrimental impact of SAP on maternal and reproductive health in Tanzania (Richey 2004, Lugala 1995). These early studies, however, mainly focused on the consequences of introduction of individual co-pay also known as "user fees" (e.g., Litvack and Bodart 1993, Huber 1993) as opposed to long term changes in health access. 
Late 1990s and 2000s: The era of adjustment with a human face and millennium development goals

Due to growing concerns over negative social consequences of the initial implementation of SAP in the early 1990s, discussions emerged urging for more sensitivity towards adverse effects of the reforms, especially on the economically vulnerable segments of the population. As a result of these debates, "SAP with a human face" programs were implemented to alleviate the negative consequences of the previous policies on social welfare (Jolly 1991). Under these new initiatives, adjustment program started to take into consideration countries' level of indebtedness and poverty. The repackaged poor-friendly special programs included, among others, the Highly Indebted Poor Countries (HIPC) initiative and the Poverty Reduction Strategy Papers (PRSP). Tanzania was among the beneficiaries of these programs. Q ualitatively, this was a beginning of a new era of adjustment more cognizant of "human cost" of adjustment demarcating the early 1990s era of stringent loan conditions. The late 1990s to early 2000s period was also characterized by massive global initiatives aiming to reduce extreme poverty, such as the Millennium Development Goals, which listed reduction of maternal and child morbidity and mortality among its priorities.

\section{Hypotheses}

Given these structural transformations, I posit that determinants of maternal health access in the 1990 to 2010 period, specifically the effect of household wealth, would vary by context.

(i) Place context hypothesis: Following the termination of the community-oriented ujamaa, during the individual-oriented privatization and liberalization era (1990 onwards) household wealth is a stronger predictor of utilization of professional maternal health services than place characteristics (regional wealth and urban/rural residence).

(ii) Period context hypothesis: All households, regardless of their wealth level, experienced improved access to maternal health services in the 2000s post-liberalization era of massive extreme poverty eradication initiatives, such as the Millennium Development Goals, relative to the 1990s period of privatization and structural adjustment.

\section{Data and methods Data}

Statistical data for this paper were obtained from nationally representative Demographic and Health Surveys (DHS) by pooling four rounds of standard Tanzania DHS collected in 1996, 1999, 2004-05, and 2010. I used the retrospective fertility histories (Birth Files) which contain vital statistics for all children born to an interviewed woman. To reduce recall bias, I limited the analysis in this paper to children born in the five year period preceding a given survey. The pooled birth files from the four DHS data collection rounds in Tanzania thus cover children born between 1990 and 2010 with a total of 28,605 live births. I finally merged the pooled Birth Files with information on household and community characteristics available in the DHS individual (women) data files.

\section{Variables and measures}

I used utilization of birth delivery services from medically-trained personnel as the dependent variable. This variable was coded as 1 if a birth delivery attendant was a medically-trained professional (i.e., a doctor, a nurse or a midwife, an auxiliary midwife or an $\mathrm{MCH}$ aide, a clinical officer, or an assistant clinical officer), and was coded as 0 if otherwise.

Independent variables include known determinants of use of professional maternal care which includes mother's demographic attributes (age, education, and parity/birth order), household wealth, and place of residence. For mothers' age, I also included an age-squared variable to capture the non-linear effect of age. I categorized mothers' educational attainment using three dummy variables corresponding to no education, primary education, and secondary education or higher.

I adopted the DHS composite index of household wealth, which is calculated from households' ownership of selected assets, as a background measure of household socioeconomic status. I used the categorical version of the index which groups households into five quintiles of the factor analysis scores ranging from one, lowest wealth, to five, highest wealth. I categorized households as low Socioeconomic Status (SES) households if they fall in the $1^{\text {st }}$ or $2^{\text {nd }}$ quintile, mid SES if they fall in the $3^{\text {rd }}$ or the $4^{\text {th }}$ quintile, and as high SES if they fall in the top quintile. I also computed means of the factor scores on the wealth index by region, which I used as a proxy for the overall wealth level of a given region.

In addition, I created two measures of place of residence including a dummy variable indicating 
whether a household is located in an urban area and an identifier of region. Regions are the second administrative unit in Tanzania below the state level. The pooled DHS data contained information from all regions of the union government including 22 from mainland Tanzania and five from the isles of Zanzibar and Pemba."

Furthermore, I added an identification of calendar year to capture the serial trend in services utilization by coding 1990 - 2010 as 1-20. The year variable was also broken into two period dummies to separate the $1990 \mathrm{~s}$ period, the peak of liberalization, from the $2000 \mathrm{~s}$, the post-liberalization era of anti-poverty initiatives, such as the Millennium Development Goals project.

Finally, I created interaction variables to examine the hypothesized contextual changes of the effect of household wealth by place and time. The first set of interaction variables are two household wealth/SESplace interaction variables including household wealth (as low, mid, or high SES) interacted with regional mean wealth and household SES interacted with urban location. The second set of interaction variables incorporated three wealth-period interactions including household wealth (as low, mid, or high-SES) interacted with the dummy identifier for the 2000s post-liberalization period, regional mean wealth interacted with the dummy for the 2000 s period, and urban residence interacted with the dummy for the 2000 s period.

\section{Analytical technique}

Since the dependent variable is binary, I apply logistic regression models. I start with a basic logistic model predicting log-odds of having had a birth assisted by a medically-trained professional using the following predictors: mothers' age and education, household wealth, birth order, urban residency, and year. The logit estimation was as follows:

$\log [\pi /(I-\pi)]=B_{0}+B_{1}$ Age $+B_{2}$ Age Squared + $B_{3}$ Education $+B_{4}$ Household Wealth $+B_{5}$ Urban + $B_{6}$ Year

where $\pi$ is the probability than an infant's mother received professional delivery care.

Then, in order to account for regional effects, I re-estimated the logistic regressions using a multilevel set up. Multilevel regression models take into account clustering (shared attributes) among social units in the same level of analysis. The multilevel option also allows the logistic model to take into account unobserved regional-specific heterogeneity. I therefore estimated a two-level model with child/mother-level as level one and region of residence as level two. I used the "random intercept" variety of multilevel modeling which allows each region $j$ 's intercept to differ from an average region by a between region variance $u_{0}$, the so called "random effect" (Rabe-Hesketh and Skrondal 2008).

The generic multilevel logistic model of log-odds of mother of child $i$ born in region $j$ having utilized professional birth delivery services is thus as follows: $\log \left[\pi_{i j} /\left(I-\pi_{i j}\right)\right]=B_{0}+B_{1}$ Age $_{i j}+B_{2}$ Age Squared $_{i j}+$ $B_{3}$ Education $_{i j}+B_{4}$ Household Wealth $_{i j}+B_{5}$ Urban $_{i j}+$ $B_{6} Y_{\text {ear }}+U_{0 j}$

where $\pi_{i j}$ is the probability that infant i's mother in region $j$ utilized professional birth delivery services, $B_{0}$ is the intercept shared by all regions, and $U_{0 j}$ is the random effect specific to region $j$.

I finally estimated series of models with interaction variables to examine how the effect of household wealth varies by the two hypothesized contextual variables: place and period. I ran two sets of models. Models in the first set examined the place context whereas the second set explored the period context. These were expanded models building on the basic model above. For the first set (place context), I estimated two expanded models by adding the following interaction variables to the above model: (i) household wealth interacted with region of residence's mean wealth and (ii) urban residency interacted with region of residence's mean wealth. For the second set (period context), I estimated three expanded models adding one set of interaction variables at a time starting with (i) household wealth interacted with the dummy for 2000 s period, (ii) regional mean wealth interacted with the dummy for the 2000 s period, and (iii) urban residency interacted with the 2000 s period.

All regressions were estimated using STATA.

\section{Results}

\section{Summary statistics}

Raw yearly data from the World Bank's development indicators show an upward trend in both the proportion of births attended by skilled staff and proportional of pregnant women receiving prenatal care (Figure 1). There was, however, a slight decline in access to these services in the 1990s. 
Figure 1: Percent of W omen Receiving Maternal Health Care, 1990-2010

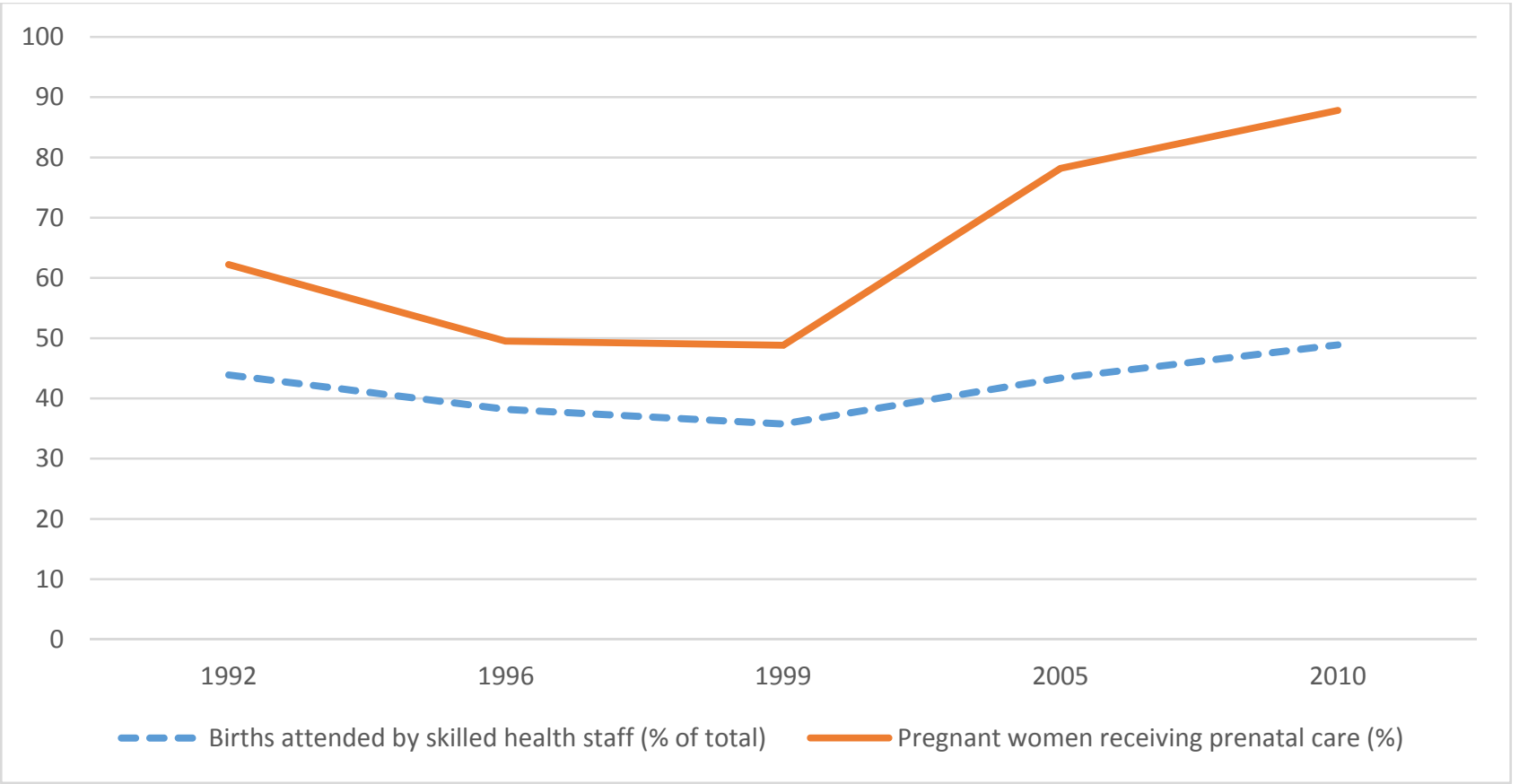

Source: W orld Development Indicators, World Bank.

The relationship between household SES and utilization of professional delivery services varies by region. In overall, the higher the household's SES the higher the likelihood of a household member seeking birth delivery services from a medicallytrained professional. However, as Figure 2 shows, the difference between the proportion of women from poor (low SES) households and the proportion from rich (high SES) household seeking these services varies by region. For example, rich-poor in utilization is higher in Dodoma and Kigoma compared to Kilimanjaro and D ar es Salaam. 
Figure 2: Proportion of women WHO utilized birth delivery services from medically-trained professionals categorized by household SES in selected regions of Tanzania, DHS, 1990-2010.

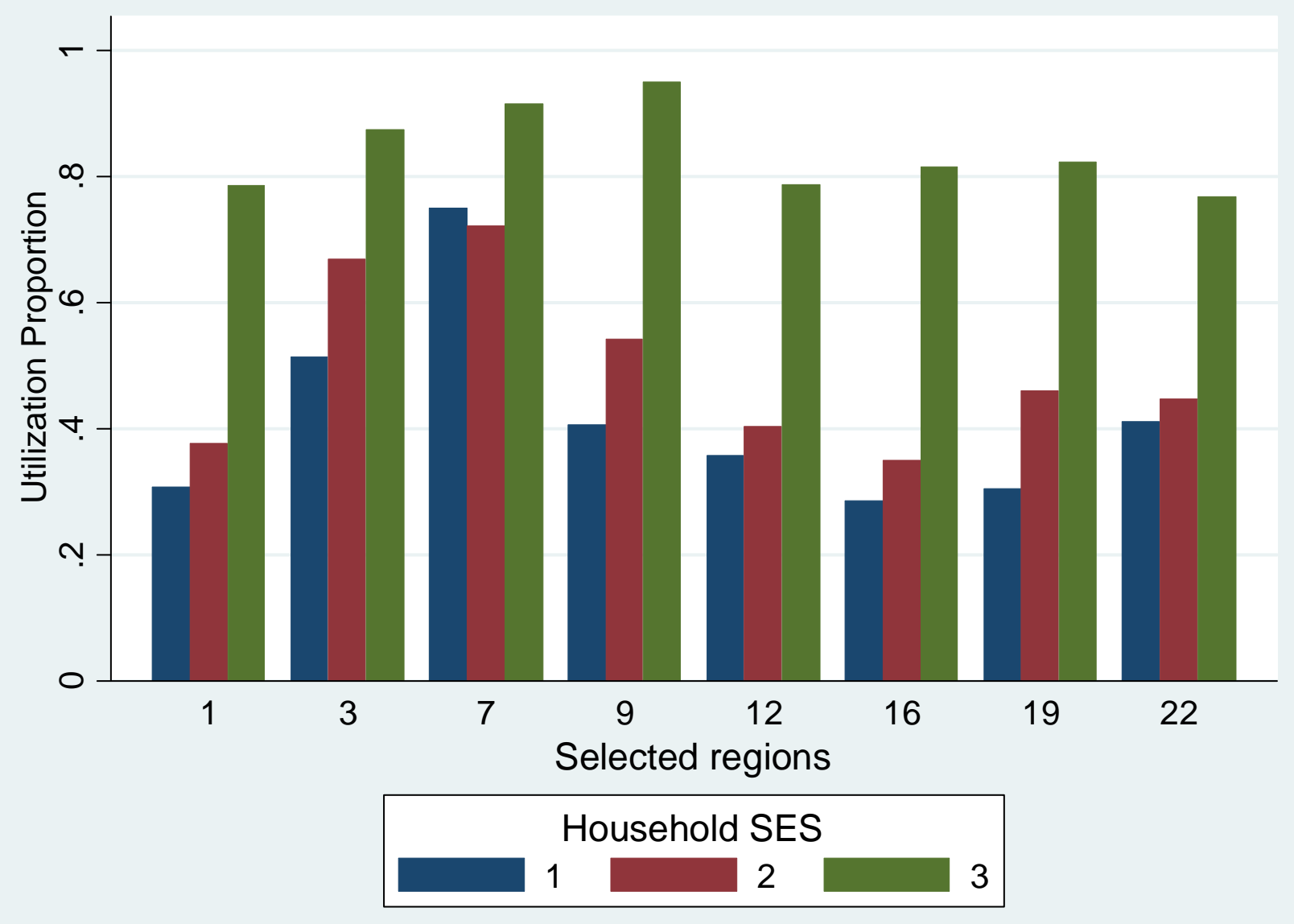

SES key: $1=$ low SES, $2=$ mid SES, $3=$ high SES

Region key: 1=D odoma, 3=Kilimanjaro, 7-D ar es Salaam, $9=$ Mtwara, 12= Mbeya, 16=Kigoma, 19= Mwanza, $22=$ Zanzibar

On the other hand, the yearly relative difference between proportions of low and high SES household members seeking professional delivery care is not as pronounced. Across all years, the proportion of women from high SES household who utilized professional delivery services is consistently higher than those from low and mid SES with difference between low and high SES only changing slightly (Figure 3). 
Figure 3: Proportion of women who utilized birth delivery services from medically-trained professionals categorized by household SES in Tanzania in selected years, DHS, 1990-2010.

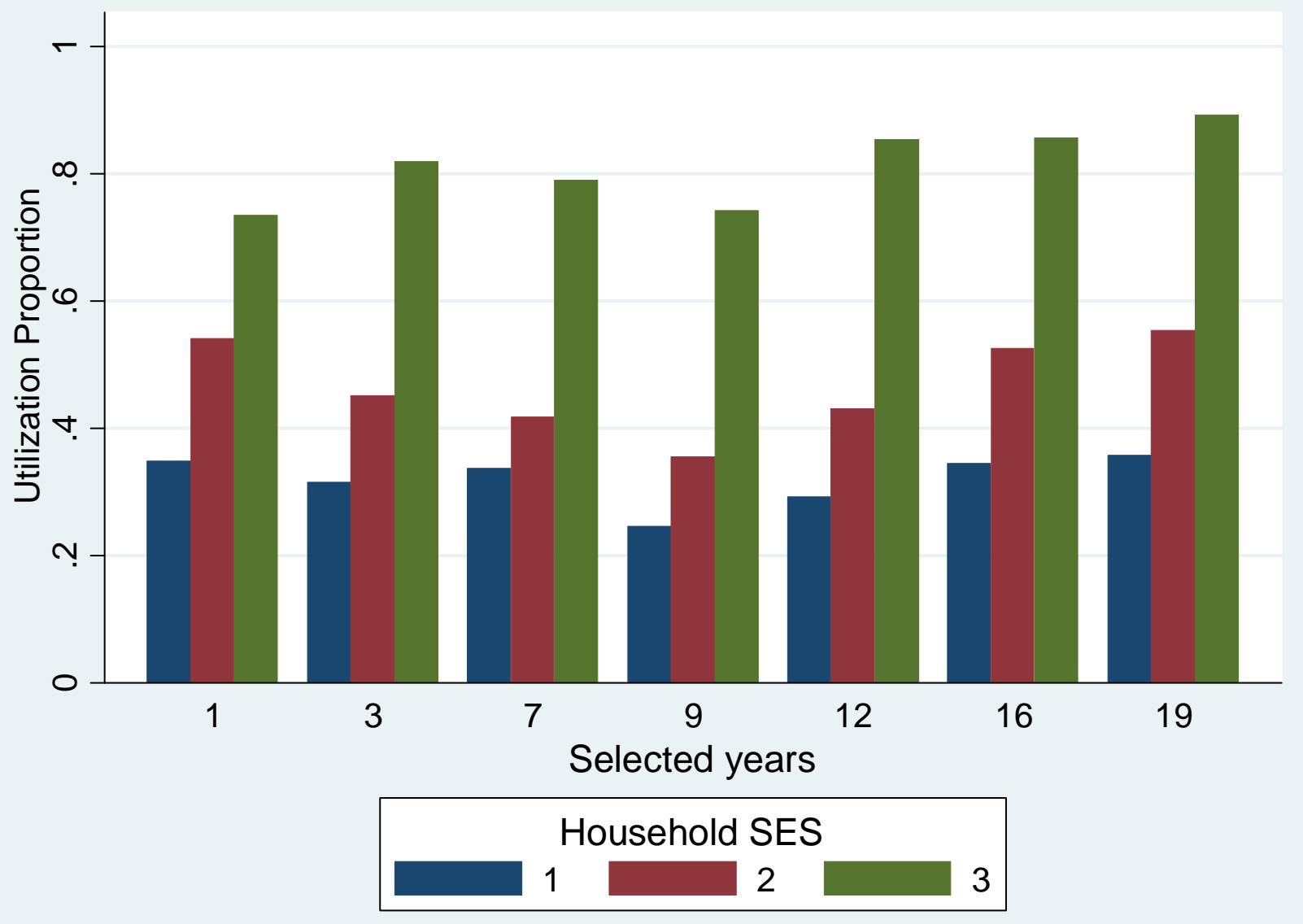

SES key: $1=$ low SES, $2=$ mid SES, $3=$ high SES

Year key: $1=1991,3=1993,7-1997,9=1999,12=2002,16=2006,19=2009$

Logistic vs. contextual multilevel logistic models of predictors of use of professional maternal health services

Congruent with other studies, the logistic regressions results (Table 1 models la and $\mathrm{Ib}$ ) show that education, household wealth, and being a resident of an urban area increases the log odds of having used birth delivery assistance from medicallytrained professionals, whereas the log odds decrease with mothers' age and birth order/parity. Also, log odds of receiving professional delivery care increase with calendar year, which points to the expansion of access over time. 
African Population Studies Vol 28 no 2 Supplement July 2014

Table 1: Comparison of logistic and multilevel estimates of predictors of birth delivery by a medically-trained professional in Tanzania, DHS, 1990-2010 $(\mathrm{N}=28,605)$

\begin{tabular}{lcccc}
\hline & Model I(a) & Model I(b) \\
\hline & Coeff. & $P>|z|$ & Coeff. & $P>|z|$ \\
\hline Mother's age & -0.051 & 0.000 & -0.050 & 0.001 \\
\hline Mother's age squared & 0.002 & 0.000 & 0.001 & 0.000 \\
\hline Birth order & -0.228 & 0.000 & -0.186 & 0.000 \\
\hline Education (no educ as ref) & & & & \\
\hline$\quad$ Primary education & 0.623 & 0.000 & 0.565 & 0.000 \\
\hline Secondary education or higher & 0.745 & 0.000 & 0.926 & 0.000 \\
\hline Household wealth (low SES as ref) & & & & \\
\hline$\quad$ Mid SES & 0.388 & 0.000 & 0.417 & 0.000 \\
\hline$\quad$ High SES & 1.336 & 0.000 & 1.366 & 0.000 \\
\hline Urban & 1.098 & 0.000 & 1.061 & 0.000 \\
\hline Year & 0.009 & 0.000 & 0.014 & 0.000 \\
\hline Constant & -0.359 & 0.096 & -0.324 & 0.185 \\
\hline
\end{tabular}

Variance of random effect $U_{0 j}$

(std. error in parentheses)

$0.23(0.07)$

LR test for R.E vs. Logistic 1052.640

0.000

Likelihood ratio tests comparing the logistic estimation with the multilevel logistic estimation show an improvement in model-fit when the random effects are included in the multilevel setup (the likelihood ratio chi-squared tests had $p$ value $=0.000$ ).

\section{How place of residence changes the effect of household wealth on the likelihood of utilizing professional birth delivery services}

The results shows that, on its own, the regional average wealth does not have an additional

statistically significant effect on the likelihood of seeking delivery assistance from professionals net of household wealth and the other predictors (Table 2 model Ila). However, the effect of own household's wealth has a statistically significant interactive effect with regional average wealth with the gap in utilization between low and high SES households diminishing as regional average wealth increases (Table 2 model IIb). 
Table 2: The effect of place on determinants of birth delivery by a medically-trained professional in Tanzania, DHS, $1990-2010(\mathrm{~N}=28,605)$

\begin{tabular}{|c|c|c|c|c|c|c|}
\hline & \multicolumn{2}{|c|}{ Model II(a) } & \multicolumn{2}{|c|}{ Model II (b) } & \multicolumn{2}{|c|}{ Model II(c ) } \\
\hline & Coeff. & $P>|z|$ & Coeff. & $P>|z|$ & Coeff. & $P>|z|$ \\
\hline Mother's age & -0.050 & 0.001 & -0.051 & 0.001 & -0.050 & 0.001 \\
\hline Mother's age squared & 0.001 & 0.000 & 0.001 & 0.000 & 0.001 & 0.000 \\
\hline Birth order & -0.186 & 0.000 & -0.186 & 0.000 & -0.185 & 0.000 \\
\hline \multicolumn{7}{|l|}{ Education (no educ as ref) } \\
\hline Secondary education or higher & 0.925 & 0.000 & 0.940 & 0.000 & 0.935 & 0.000 \\
\hline \multicolumn{7}{|l|}{ Household wealth (low SES as ref) } \\
\hline Mid SES & 0.416 & 0.000 & 0.932 & 0.000 & 0.402 & 0.000 \\
\hline High SES & 1.364 & 0.000 & 2.526 & 0.000 & 1.369 & 0.000 \\
\hline Urban & 1.060 & 0.000 & 1.056 & 0.000 & 2.305 & 0.000 \\
\hline Year & 0.014 & 0.000 & 0.015 & 0.000 & 0.014 & 0.000 \\
\hline Mid SES*Regional wealth & & & -0.187 & 0.009 & & \\
\hline High SES*Regional wealth & & & -0.383 & 0.000 & & \\
\hline Urban*Regional wealth & & & & & -0.407 & 0.000 \\
\hline Constant & -0.855 & 0.127 & -1.468 & 0.013 & -1.301 & 0.024 \\
\hline Variance of random effect $U_{0 j}$ (std. error in parentheses) & $0.22(0.07)$ & & $0.23(0.07)$ & & $0.23(0.07)$ & \\
\hline LR test for R.E vs Logistic & 1038.460 & 0.000 & 1056.010 & 0.000 & 1067.630 & 0.000 \\
\hline
\end{tabular}

The urban/rural effect also varies by regions' average wealth. The gap between rural and urban areas in utilization of professional delivery services is lower in wealthier regions (Table 2 model IIc). As illustrated on Figure 4 using predicted probabilities, the difference in predicted probability of using professional birth delivery services between rural and urban dwellers is higher in poor regions $\left(1^{\text {st }}\right.$ quartile in the regional wealth distribution) than in in wealthy regions ( $4^{\text {th }}$ quartile). 
Figure 4: How the effect of residing in rural or urban area on the probability of utilizing medical birth delivery services vary by regional wealth, DHS, 1990-2010

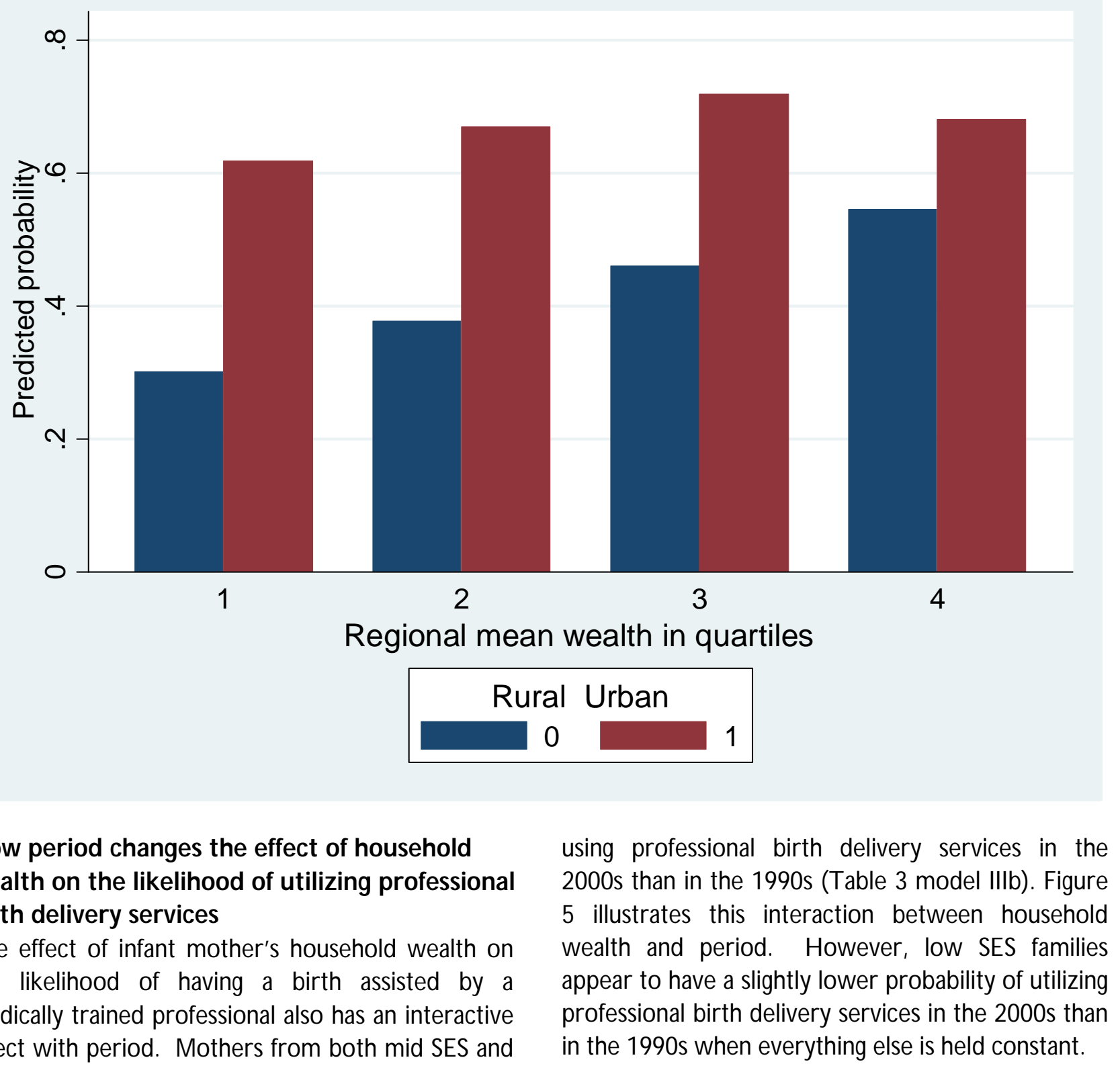


Table 3: The effect of period on determinants of birth delivery by a medically-trained professional in Tanzania, DHS, $1990-2010(\mathrm{~N}=28,605)$

\begin{tabular}{|c|c|c|c|c|c|c|c|c|}
\hline & \multicolumn{2}{|c|}{ Model III(a) } & \multicolumn{2}{|c|}{ Model III(b) } & \multicolumn{2}{|c|}{ Model III(c) } & \multicolumn{2}{|c|}{ Model III(d) } \\
\hline & Coeff. & $P>|z|$ & Coeff. & $P>|z|$ & Coeff. & $P>|z|$ & Coeff. & $P>|z|$ \\
\hline Mother's age & -0.051 & 0.001 & -0.051 & 0.001 & -0.051 & 0.001 & -0.051 & 0.001 \\
\hline Mother's age squared & 0.001 & 0.000 & 0.001 & 0.000 & 0.001 & 0.000 & 0.001 & 0.000 \\
\hline Birth order & -0.185 & 0.000 & -0.184 & 0.000 & -0.183 & 0.000 & -0.185 & 0.000 \\
\hline \multicolumn{9}{|l|}{ Education (no educ as ref) } \\
\hline Secondary education or higher & 0.927 & 0.000 & 0.907 & 0.000 & 0.918 & 0.000 & 0.927 & 0.000 \\
\hline \multicolumn{9}{|l|}{ Household wealth } \\
\hline Mid SES & 0.417 & 0.000 & 0.276 & 0.000 & 0.407 & 0.000 & 0.417 & 0.000 \\
\hline High SES & 1.367 & 0.000 & 1.105 & 0.000 & 1.363 & 0.000 & 1.367 & 0.000 \\
\hline Urban & 1.061 & 0.000 & 1.059 & 0.000 & 1.074 & 0.000 & 1.030 & 0.000 \\
\hline Year & 0.011 & 0.034 & 0.011 & 0.026 & 0.011 & 0.027 & 0.011 & 0.034 \\
\hline Mid SES*2000s period & & & 0.218 & 0.000 & & & & \\
\hline High SES*2000s period & & & 0.447 & 0.000 & & & & \\
\hline Regional wealth & & & & & 0.031 & 0.859 & & \\
\hline Regional wealth*2000s period & & & & & 0.284 & 0.000 & & \\
\hline Urban*2000s period & & & & & & & 0.050 & 0.543 \\
\hline Constant & -0.301 & 0.220 & -0.189 & 0.444 & -0.384 & 0.505 & -0.297 & 0.228 \\
\hline $\begin{array}{l}\text { Variance of random effect } U_{0 j} \\
\text { (std. error in parentheses) }\end{array}$ & $0.23(0.07)$ & & $0.24(0.07)$ & & $0.23(0.07)$ & & $0.23(0.07)$ & \\
\hline LR test for R.E vs. Logistic & 1053.23 & 0.000 & 1065.31 & 0.000 & 1062.82 & 0.000 & 1053.57 & 0.000 \\
\hline
\end{tabular}


Figure 5: How the effect of urban/rural residence on the probability of utilizing medical birth delivery services differs between the 1990 s period compared to the 2000 s period, DHS, 1990-2010

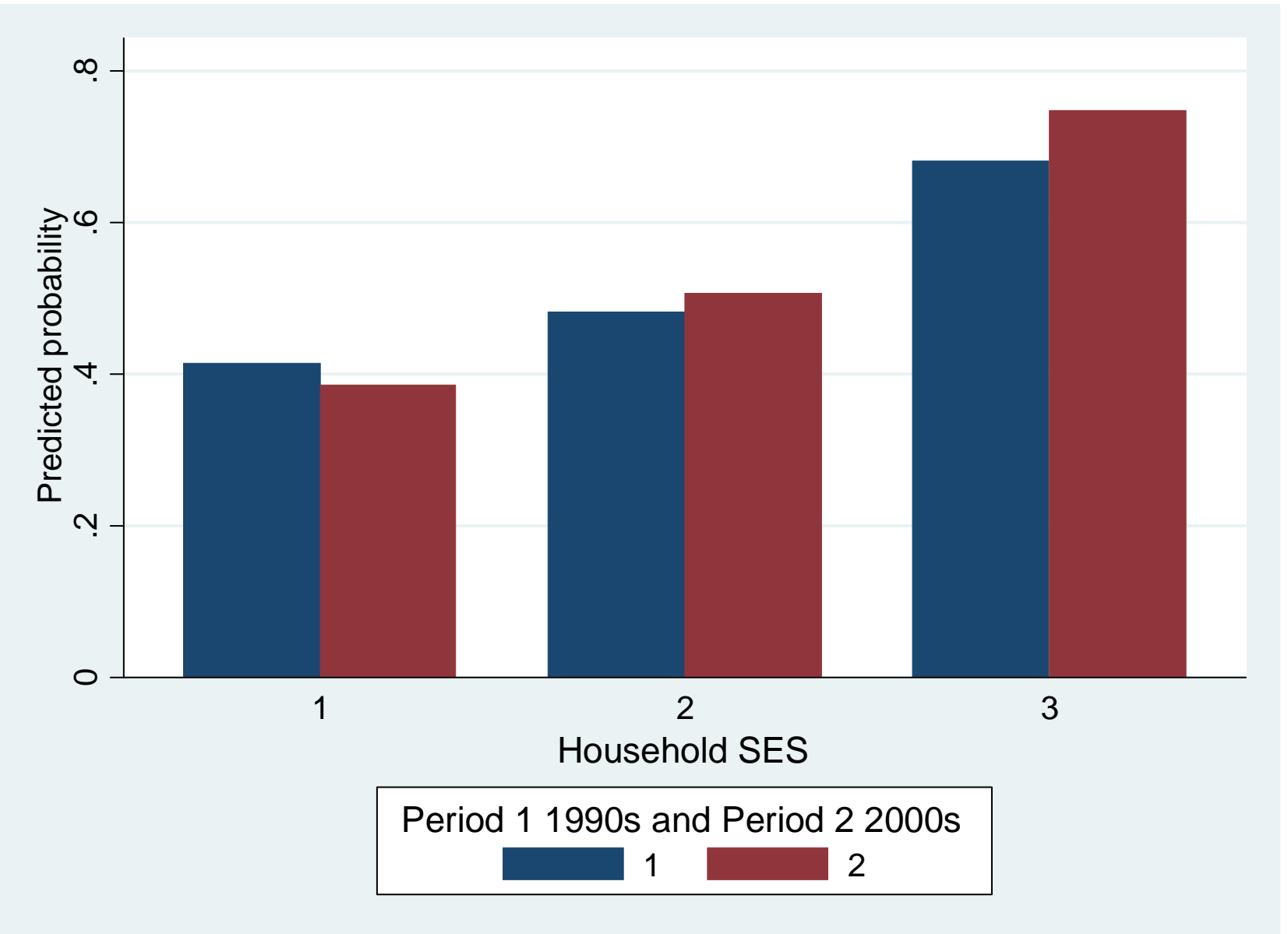

Also, regional wealth seems to have a bigger impact on utilization of professional delivery services in the 2000s relative to the 1990s (Table 3 model IIIC). However, the results do not yield statistically significant effects for an interaction between urban residency and period (Table 3 model IIId). That is, even though in itself residing in urban areas enhances the likelihood of using professional delivery care, this effect does not differ between the 1990s period relative to the 2000 s period.

\section{Discussion}

This paper uses DHS data on utilization of maternal health services to illustrate how context interacts with individual and household characteristics, especially household SES, in predicting the likelihood of using birth delivery services from medicallytrained experts. Similar to studies which have explored other low-income countries, in Tanzania, educated women, women from wealthy households, and those residing in urban areas are more likely to seek maternal health services from professionals. Also, the analysis finds that utilization has been improving over time.

More importantly, the results point to persisting inequalities in utilization of professional maternal care services both across geographical space and over time. The analysis shows that living in a region that is relatively wealth buffers the negative impact of having low wealth, meaning infrastructural advantages of a place where one lives still matter in determining use and access to maternal health facilities. The existed inequalities between regions, which ujamaa policies attempted to alleviate, are thus manifested in the observed disparities in maternal health access.

The analysis also finds that utilization of professional maternal health services in the postliberalization 2000s is higher among mid and high SES households than among low SES households signaling to a potentially growing inequality. Maternal health utilization by low SES household appears to have decreased in the 2000 s relative to the 1990s according to the analysis. This result thus supports the idea of expanding maternal health services targeting the poor, which is the idea behind initiatives such as Millennium Development Goals.

This paper calls for more research that examines the links between structural changes and demographic outcomes especially since Social Demography has a methodological comparative 
advantage at highlighting long-trends using comprehensive datasets such as DHS. The analysis shows that overall trends can mask remarkable heterogeneity across groups in different places and different time periods. Such differences can be made legible when the aggregate demographic trends are explored in relation to the wide social context as done in this paper.

Finally, the limitations of the analysis conducted in this paper should also be taken into consideration. In this paper, use of the aforementioned maternal care services was considered synonymous with access because the objective of the analysis and the paper is to draw conclusions on how structural reforms potentially changed the context of health care access in Tanzania. Such an extrapolation is not as misleading since research shows that in lowincome nations, utilization of health services is highly conditioned by access rather than preferences (Kruk, Rockers, et al. 2010; M baruku, Msambichaka et al. 2009; Kowalewski, Mujinja, and Jahn 2002). However, if data on individual preferences for maternal health services from medical professionals were available, stronger conclusions could have been drawn. Also, having data on other predictors of service utilization, such as distance to a clinic or cost of services, would have improved the analysis. Information on distance to a health center and data on medical costs was not available in all of the four Tanzania DHS used.

\section{Conclusion}

Determinants of utilization of maternal and reproductive health services in low-income nations include demographic attributes, household circumstances, and community context. This paper focused on the interaction effect between household wealth/SES and context (both place and period). The overarching objective was to highlight the link between a shifting political-economic context and health access in Tanzania. The political-economic changes included budget austerity measures that led to a shift from government sponsored health services to individual responsibility through user fees and economic restructuring through privatization.

The analysis showed that the effect of household wealth on the likelihood of accessing professional maternal services is conditioned on place (region) characteristics. The results are contrary to the stated hypothesis, which speculated that personal and household wealth would be the paramount predictor of utilization of professional maternal health services in the individual-focused liberalization era. The analysis shows that women from low SES households living in a relatively wealthier region have a higher likelihood of using professional maternal health services than their counterparts from poorer regions.

Also, contrary to the second hypothesis, not all household types show a statistically significant increase in odds of utilizing professional birth delivery services in the 2000s. The impact of household SES on professional maternal health utilization varies between the 1990s and the 2000s period. Mid and high SES households enjoyed an increase in utilization of these services in the 2000s relative to the 1990s, whereas low SES household show a slight decline.

To sum up, the analysis and the results in this paper show that there is a wide variation among groups in utilization of professional maternal health services regardless of the observed overall improvement in access. Place matters. Poor households in wealthy regions are better off than their counterparts in poor regions. Rural residents from wealthy region are also better off than their counterparts in poor regions. In addition, the analysis shows that the improvements in health access have not been enjoyed by all. Poor households are worse off in the post-liberalization 2000 s period relative to the 1990 s.

\section{References}

Anwar, A. I., Killewo, J., Chowdhury, M.-E.-E. K., and Dasgupta, S. K. 2005. "Bangladesh: inequalities in utilization of maternal health care services evidence from Matlab." In D. R. Gwatkin, A. Wagstaff, \& A. S. Yazbeck (Eds.), Reaching the poor with health, nutrition, and population services: What works, what doesn't, and why. Washington, DC: The World Bank.

Amani, H.K., Wangwe S.M, et al. 2006. "Understanding Economic and Political Reforms in Tanzania," in Joseph Mensah (Ed) Understanding Economic Reforms in Africa: A Tale of Seven Nations. Palgrave Macmillan, New York.

Gibbon, P. 1995. "Merchantisation of Production and Privatisation of Development in Post-Ujamaa Tanzania," in Gibbon Peter (Ed), Liberalised Development in Tanzania: Studies on Accumulation Processes and Local institutions. Nordiska Afrikainstitutet. Uppsala, Sw eden.

Glei, D. A., Goldman, N., \& Rodriguez, G. 2003. "Utilization of care during pregnancy in rural Guatemala: does obstetrical need matter?" Social Science \& Medicine 57, (12):2447-2463.

Guliani, H, Sepehri, A, and Serieux, J. 2010. "What impact does contact with the prenatal care 
system have on women's use of facility delivery? Evidence from low-income countries." Social Science \& Medicine 74, (12): 1882-1890.

Hydén, G. 1980. Beyond Ujamaa in Tanzania: Underdevelopment and an Uncaptured Peasantry. London: Heinemann.

Jennings, M. 2008. Surrogates of the State: NGOs, Development, and Ujamaa in Tanzania. Bloomfield, CT: Kumarian Press.

Jolly, Richard. 1991. "Adjustment with a Human Face: A UNICEF Record and Perspective on the 1980s." World Development 19, (12):1807-1821.

Khan, K.S., W ojdyla, D., Say L., Gulmezoglu, A.M, Van Look, P.F. 2006. "WHO analysis of causes of maternal death: a systematic review." Lancet 367:1066-74

Kowalewski, M, Mujinja P. and Jahn, A. 2002."Can Mothers Afford Maternal Health Care Costs? User Costs of Maternity Services in Rural Tanzania." African Journal of Reproductive Health $6,(1): 65-73$.

Kruk M.E., Rockers P.C., Mbaruku, G., Paczkowski,M.M. and Galea,S. 2010 "Community and health system factors associated with facility delivery in rural Tanzania: A multilevel analysis." Health Policy 97, (2-3): 209-216.

Lugala, J.L. 1995. "The Impact of Structural Adjustment Policies on Women's and Children's Health in Tanzania." Review of African Political Economy 22,(63): 43-53.

Lopez-de-Silanes, $F \&$ Chong, A. 2002. "Privatization and labor force restructuring around the world." World Bank Working Paper 2884. Washington DC.

Magadi, M. A., 2004. "Maternal and child health among the urban poor in Nairobi, Kenya" African Population studies Supplement B, Population and Health Issues in Africa 19:179-198.

Magadi, M. A., Zulu, E. and Brockerhoff, M. 2003. "The Inequality of Maternal Health in U rban subSaharan Africa" Population Studies 57,3,:349-368.

Mbaruku, G., Msambichaka, B.,Galea, S., Rockers, P.C., Kruk,M.E. 2009 "Dissatisfaction with traditional birth attendants in rural Tanzania." International Journal of Gynecology \& Obstetrics 107, (1):8-11.

Mkenda, B.K. 2005. "The Impact of Globalisation on Tanzania's Labour Market:Evidence from the Manufacturing Sector." A paper prepared for a Policy Dialogue for Accelerating Growth and Poverty Reduction in Tanzania, held at the Conference hall, ESRF, on July 28th, 2005.
Mrisho, M., Schellenberg, J. A., Mushi, A. K., O brist, B., Mshinda, H., Tanner, M., et al. 2007. "Factors affecting home delivery in rural Tanzania." Tropical Medicine and International Health, 12, (7): 862-872.

Mwandenga, A.M. (2000). "Socio-economic Impact of Privatization: The Tanzanian Experience." The African Journal of Finance and Management 9,(1):43-58.

Nyerere, J.K. 1985. Nyerere on Socialism. Oxford: O xford U niversity Press.

Nyerere, J. K. 1973. Essays on Socialism. Oxford: 0 xford U niversity Press.

N yerere, J.K. 1968. Freedom and Socialism. Oxford: 0 xford U niversity Press.

Paul, B. K., \& Rumsey, D. J. 2002. "Utilization of health facilities and trained birth attendants for childbirth in rural Bangladesh: an empirical study." Social Science\& Medicine 54, (12): 17551765.

Rabe-hesketh, S. and Skrondal, A. 2008. Multilevel and Longitudinal Modelling using STATA (Second Edition). College Station, TX: Stata Press.

Richey, Lisa Ann. 2004. "From the Policies to the Clinics: The Reproductive Health Paradox in Post-Adjustment Health Care." World Development 32,(6): 923-940.

Scott, J.C. 1980. Seeing Like a State: How Certain Schemes to Improve the Human Condition Have Failed, New Haven and London: Yale Agrarian Studies, Yale U niversity Press.

Schneider, L. 2007. "High on Modernity? Explaining the Failings of Tanzanian Villagisation." African Studies, 66, (1): 9-38

Schneider, L. 2010. "Freedom and Unfreedom in Rural Development: Julius Nyerere, Ujamaa Vijijini, and Villagization." Canadian Journal of African Studies 38, (2):344-392.

Shivji I., and Peter, C. 2003. Village Democracy Initiative Report. Prepared for The President's O ffice - Regional Administration and Local Government.

Stein, H. 1991. "Economic Policy and the IMF in Tanzania: Conditionality, Conflict, and Convergence," in H. Campbell and H. Stein (eds), The IMF and Tanzania: The Dynamics of Liberalization. Harare: SAPES Books.

Stekelenburg, J., Kyanamina, S., Mukelabai, M., Wolffers, I., and van Roosmalen, J. 2004. "W aiting too long: low use of maternal health services in Kalabo, Zambia." Tropical Medicine and International Health 9,(3):390-398. 
Stephenson, R., Baschieri, A., Clements, S., Hennink, M., and Madise, N . 2006.

"Contextual influences on the use of health facilities for childbirth in Africa." Public Health Matters 96,(1):1-10.

Spangler,S.A., Bloom, S.S. 2010. "Use of biomedical obstetric care in rural Tanzania: The role of social and material inequalities." Social Science \& Medicine 71, (4):760-768.

Tann, C. J., Kizza, M., Morison, L., Mabey, D., Muwanga, M., Heiner, G., et al. 2007. "Use of antenatal services and delivery care in Entebbe, U ganda: a community based survey". BMC Pregnancy and Childbirth, 7(23):1-11.

Tawiah, E.O. 2011. "Maternal health care in five sub-Saharan African countries." African Population Studies 25, (1):1-25

Van Rijsbergen, B. and D'Exelle, B. 2013. "Delivery Care in Tanzania: A Comparative Analysis of U se and Preferences." World Development 43: 276287.

World Bank. 2013. World Development Indicators. http://data.worldbank.org/. Accessed October $15^{\text {th }} 2013$.
Yanagisawa, S., O um, S., and Wakai, S. 2006. "D eterminants of skilled birth attendance in rural Cambodia." Tropical Medicine and International Health 11, (2):2238-2251

\footnotetext{
i Life time risk of maternal death is the probability that a 15 -year-old female will die eventually from a maternal cause assuming that current levels of fertility and mortality (including maternal mortality) do not change in the future.

ii For consistency across rounds of the DHS data, I merged recently created regions, such as Manyara, with the main region which they were a district of before becoming stand-alone regions. The same applies to the new regions from isles Zanzibar and Pemba. Ultimately, the data thus incorporated 22 regions ( 20 from mainland and 2 from the islands), which corresponds to 1990 s regional divisions.
} 